\title{
Implementing a Respiratory Therapist-Driven Continuous Albuterol Weaning Protocol in the Pediatric ICU
}

\author{
Danielle K Maue, Alvaro J Tori, Andrew L Beardsley, Nadia L Krupp, Acrista J Hole, \\ Elizabeth AS Moser, and Courtney M Rowan
}

\begin{abstract}
BACKGROUND: Status asthmaticus is one of the most frequent admission diagnoses in the pediatric ICU (PICU). Collaboration between respiratory therapists (RTs) and physicians may help efficiently deliver care to a patient in status asthmaticus. The Pediatric Asthma Severity Score (PASS) is a measure of severity of a patient's asthma exacerbation at a point in time. The aim of this quality improvement initiative was to establish an RT-driven continuous albuterol weaning protocol using the PASS score. We hypothesized that this would decrease the duration of continuous albuterol without increasing adverse events. METHODS: This was a single-center implementation study in the PICU of a quaternary care children's hospital. Patients with a diagnosis of status asthmaticus who met criteria on continuous albuterol between September 2015 and September 2017 were included. An interdisciplinary team established the protocol, order sets, documentation, and education for involved staff. Qualifying subjects were assessed by an RT per protocol and assigned a PASS score, and the albuterol dose was adjusted on the basis of the PASS score. RESULTS: We compared 104 subjects studied before the implementation of this protocol (September 2015 to August 2016) to 117 subjects after the implementation of this protocol (September 2016 to October 2017). Median (interquartile range) duration of continuous albuterol in the PICU post-implementation was unchanged compared to pre-implementation: $12.1(7.2-21.0) h$ versus $11.1(6-19) h$ $(P=.22)$. Median PICU length of stay was also unchanged post-implementation compared to pre-implementation: $19.5(14.3-29.7)$ h versus $23.2(15.2-31.3)$ h $(P=.16)$. Using control charts, these processes were stable. There was no difference in adverse events. CONCLUSIONS: An interprofessionally-developed, RT-driven continuous albuterol weaning protocol can be implemented without negatively impacting duration of continuous albuterol or PICU length of stay and without increasing adverse events. Key words: asthma; quality improvement; albuterol; clinical protocols; stay; intensive care units; pediatric. [Respir Care 2019;64(11):1358-1365. (C) 2019 Daedalus Enterprises]
\end{abstract}

\section{Introduction}

Asthma is the most common chronic medical condition of childhood in the United States. ${ }^{1}$ In a recent study of our

\footnotetext{
Drs Maue, Tori, Beardsley, and Rowan are affiliated with the Department of Pediatrics, Division of Critical Care Medicine, Indiana University School of Medicine/Riley Hospital for Children at IU Health, Indianapolis, IN. Dr Krupp is affiliated with the Department of Pediatrics, Division of Pulmonology, Indiana University School of Medicine/Riley Hospital for Children at IU Health, Indianapolis, IN. Ms Hole is affiliated with the Department of Respiratory Care Services, Riley Hospital for Children at Indiana University Health, Indianapolis, IN. Ms Moser is affiliated with the Department of Biostatistics, Indiana University, Indianapolis, IN.
}

Dr Maue presented a version of this report at the annual meeting of the institution's data, it was found that asthma admissions accounted for the largest number of total pediatric ICU days compared to all other diagnoses. ${ }^{2}$ These patients require pediatric ICU (PICU) admission because status asthmaticus can be life threatening if not treated appropriately. Continuous albuterol is commonly used to treat status asthmaticus. At our institution, continuous albuterol mandates

\footnotetext{
Society for Critical Care Medicine, held February 25-28, 2018, San Antonio, Texas.

The authors have disclosed no conflicts of interest.

Correspondence: Danielle K Maue MD, 705 Riley Hospital Dr., Phase 2, 4B, Indianapolis IN, 46202. E-mail: dmaue@iu.edu.
}

DOI: $10.4187 /$ respcare. 06447 
PICU stay until the patient can be safely weaned off the medication, which is the responsibility of the physician team. Unfortunately, in a busy PICU with high acuity needs, requiring a physician assessment of an improving patient to wean albuterol may result in a delay. This exposes the patient to treatment for longer than necessary and is a poor use of medical resources.

The Pediatric Asthma Severity Score (PASS) ${ }^{3}$ (Table 1) was developed and validated in the early 2000s. ${ }^{3,4}$ It was initially used in the emergency department to help determine whether a patient required hospital admission. ${ }^{4,5} \mathrm{~A}$ recent retrospective review ${ }^{6}$ revealed that a higher PASS score at PICU admission was associated with a longer duration of continuous albuterol and length of PICU stay, increased need for noninvasive ventilation, and increased use of aminophylline, a medication typically reserved for severe presentations. ${ }^{7}$

Standardization of care has repeatedly demonstrated improved patient outcomes and cost effectiveness of care. ${ }^{8,9}$ RT-directed standardized weaning protocols have been successfully used in ICUs. Studies investigating ventilator weaning protocols carried out by RTs demonstrated that it can be effective and efficient. ${ }^{10-12}$ The aim of this implementation study was to standardize the continuous albuterol weaning protocol in the PICU using the expertise of RTs. We hypothesized that a continuous albuterol weaning protocol based on a patient's PASS score would lead to a decrease in duration of continuous albuterol treatment without increasing adverse events.

\section{Methods}

This proposed study was reviewed and exempted by the Indiana University institutional review board as a qualityimprovement project before implementation.

\section{Setting}

Our PICU is a 36-bed multidisciplinary medical/surgical unit with approximately 2,500 admissions per year, and status asthmaticus is one of the most common admission diagnoses. If a patient is on continuous albuterol, the hospital requires PICU management until they can be weaned to treatments at least $2 \mathrm{~h}$ apart. Treatment decisions for these patients, including medication weaning, traditionally have been handled by the physician team.

\section{Patient Population}

The continuous albuterol weaning protocol included all patients $\geq 2$ y old who were admitted to the PICU from September 2016 through September 2017 with a diagnosis of status asthmaticus requiring continuous albuterol. We excluded patients who required noninvasive positive-pres-

\section{QUICK LOOK}

\section{Current knowledge}

Asthma is the most common chronic medical condition in pediatrics, and status asthmaticus is a frequent admission diagnosis in the pediatric ICU (PICU). The pediatric asthma severity score (PASS) is a validated scoring system that can be used to assess a patient's asthma severity at a given point in time, and higher scores have been shown to be associated with critical care interventions. Standardization of care and protocols have been shown to improve patient outcomes, and respiratory therapist-directed standardized weaning protocols have been shown to be effective.

\section{What this paper contributes to our knowledge}

A respiratory therapist-directed, standardized, continuous albuterol weaning protocol based on the PASS can be successfully implemented in a busy PICU without increasing length of continuous albuterol or length of stay.

sure ventilation (eg, bi-level PAP or CPAP) or intubation, as well as patients receiving aminophylline or terbutaline. We also excluded patients who were on continuous albuterol for $<2 \mathrm{~h}$ in the PICU to account for patients who were taken off continuous albuterol after initial assessment by the intensivist. For the pre-intervention group, we applied the same inclusion and exclusion criteria for patients admitted from September 2015 through August 2016.

\section{Before the RT-Driven Albuterol Weaning Protocol}

Prior to implementation of this protocol, there was no standardized practice for assessing and weaning asthmatic patients on continuous albuterol. In general, a member of the physician team (eg, advanced health care provider resident, fellow, or attending physician) would assess the patient as they were able, and the physician would make decisions based on their subjective opinion of the patient's exam, informed by the individual physician's specific knowledge and experience. If the decision was made to wean, the new desired dose would be ordered by the physician and communicated to the RT. The dosages used also did not follow a protocol. For example, for a patient on $10 \mathrm{mg} / \mathrm{h}$ albuterol, some physicians would wean to $5 \mathrm{mg} / \mathrm{h}$ while others would wean straight to intermittent dosing, depending on physician preference.

\section{RT-Driven Albuterol Weaning Protocol Development and Implementation}

Between December 2015 and June 2016, a group of pediatric intensivists, a high-risk asthma pulmonologist, a 


\section{RT-Driven Albuterol Weaning Protocol}

Table 1. Calculation of PASS Scores

\begin{tabular}{|c|c|c|c|}
\hline \multirow{2}{*}{ Variables } & \multicolumn{3}{|c|}{ PASS Score } \\
\hline & 1 & 2 & 3 \\
\hline \multicolumn{4}{|l|}{ Breathing frequency } \\
\hline $2-3 y$ & $\leq 34$ breaths $/ \mathrm{min}$ & 35-39 breaths/min & $\geq 40$ breaths $/ \mathrm{min}$ \\
\hline $4-5 y$ & $\leq 30$ breaths $/ \mathrm{min}$ & $31-35$ breaths $/ \mathrm{min}$ & $\geq 36$ breaths $/ \mathrm{min}$ \\
\hline $6-12 y$ & $\leq 26$ breaths $/ \mathrm{min}$ & $27-30$ breaths/min & $\geq 31$ breaths $/ \mathrm{min}$ \\
\hline$>12 \mathrm{y}$ & $\leq 23$ breaths $/ \mathrm{min}$ & $24-27$ breaths/min & $\geq 28$ breaths $/ \mathrm{min}$ \\
\hline Oxygen requirements & $\geq 90 \%$ on room air & $85-90 \%$ on room air & $\leq 85 \%$ on room air \\
\hline Auscultation & $\begin{array}{l}\text { Normal breath sounds or end } \\
\text { expiratory wheeze only }\end{array}$ & Expiratory wheezing & $\begin{array}{l}\text { Inspiratory and expiratory wheezing } \\
\text { or diminished breath sounds }\end{array}$ \\
\hline Retractions & $\leq 1$ site & 2 sites & $\geq 3$ sites \\
\hline Dyspnea & $\begin{array}{l}\text { Speaks in sentences, coos } \\
\text { and babbles }\end{array}$ & $\begin{array}{l}\text { Speaks in partial sentences, } \\
\text { short cry }\end{array}$ & $\begin{array}{l}\text { Speaks in single words, short phrases, } \\
\text { or grunting }\end{array}$ \\
\hline
\end{tabular}

PASS $=$ Pediatric Asthma Severity Score

PICU RT supervisor, and information technology specialists held multiple meetings to establish a weaning protocol and plan education, data collection and analysis, and incorporation into the electronic medical record (Cerner Corporation, Missouri). The PASS score was already being used to wean intermittent albuterol treatments on the wards at our institution, and we had retrospective data showing that higher scores were associated with an increased duration of continuous albuterol and length of PICU stay. ${ }^{6}$ Because of these factors, the PASS score was incorporated into the continuous weaning protocol. The team reached a consensus based on previous studies done on the PASS tool as well as individual experiences. After the protocol was developed, it was incorporated into the continuous albuterol order-set within our electronic medical record.

The protocol was implemented in September 2016. When a patient with a diagnosis of status asthmaticus was admitted to the PICU on continuous albuterol, screening occurred to determine whether the patient was appropriate for the protocol. If none of the exclusion criteria were met, the patient was included unless the physician specifically ordered the discontinuation of the protocol. The original protocol is shown in detail in Figure 1.

Continuous albuterol was weaned in a standard manner by $5 \mathrm{mg} / \mathrm{h}$ at each assessment. One point of debate during protocol development was whether the patient should be weaned to $5 \mathrm{mg} / \mathrm{h}$ prior to discontinuing continuous albuterol and using intermittent treatments. The intensivist group was sent a survey via email asking providers to vote one way or the other, and it was initially decided to use $5 \mathrm{mg} / \mathrm{h}$. After interim data assessment, the protocol was modified in April 2017 to eliminate the 5-mg/h step with approval from intensivists and RTs.

Once the patient's continuous albuterol was discontinued, treatments were spaced to every $2 \mathrm{~h}$. There was already an existing protocol based on the PASS score used on the wards for further spacing treatments, so this was used in our unit. Assuming there was no other reason to remain in the ICU, the patient was then eligible for transfer to the ward.

\section{Weaning Protocol Education}

The education for this protocol was completed between May and August 2016. RT education was conducted by RT educators. The education for the RTs consisted of either a mandatory video or an in-person class as well as a competency test.

\section{Data Collection}

The pre-intervention group was initially identified from a pediatric critical care database (Virtual Pediatrics Systems, Los Angeles, California). A review of the electronic medical record was completed to confirm inclusion and apply the exclusion criteria. The subjects in the post-intervention group were obtained by querying our billing software. All patients with a diagnosis of asthma or status asthmaticus were reviewed each week. Study data were collected and managed using REDCap electronic data capture tools hosted at Indiana University. ${ }^{13}$

Data collected for each patient included demographic information, date and route of admission, history of asthma, and controller medication use. Common asthma therapies were documented, including steroids, magnesium sulfate, ipratropium bromide, supplemental oxygen use, and use of heated high-flow nasal cannula therapy. Duration of continuous albuterol and length of PICU stay were collected. Information regarding adverse events was recorded. A PASS score was calculated at PICU admission by nursing and respiratory therapy staff, using vital signs and documentation.

The goal of this protocol was to make the process of weaning continuous albuterol in the PICU more efficient 


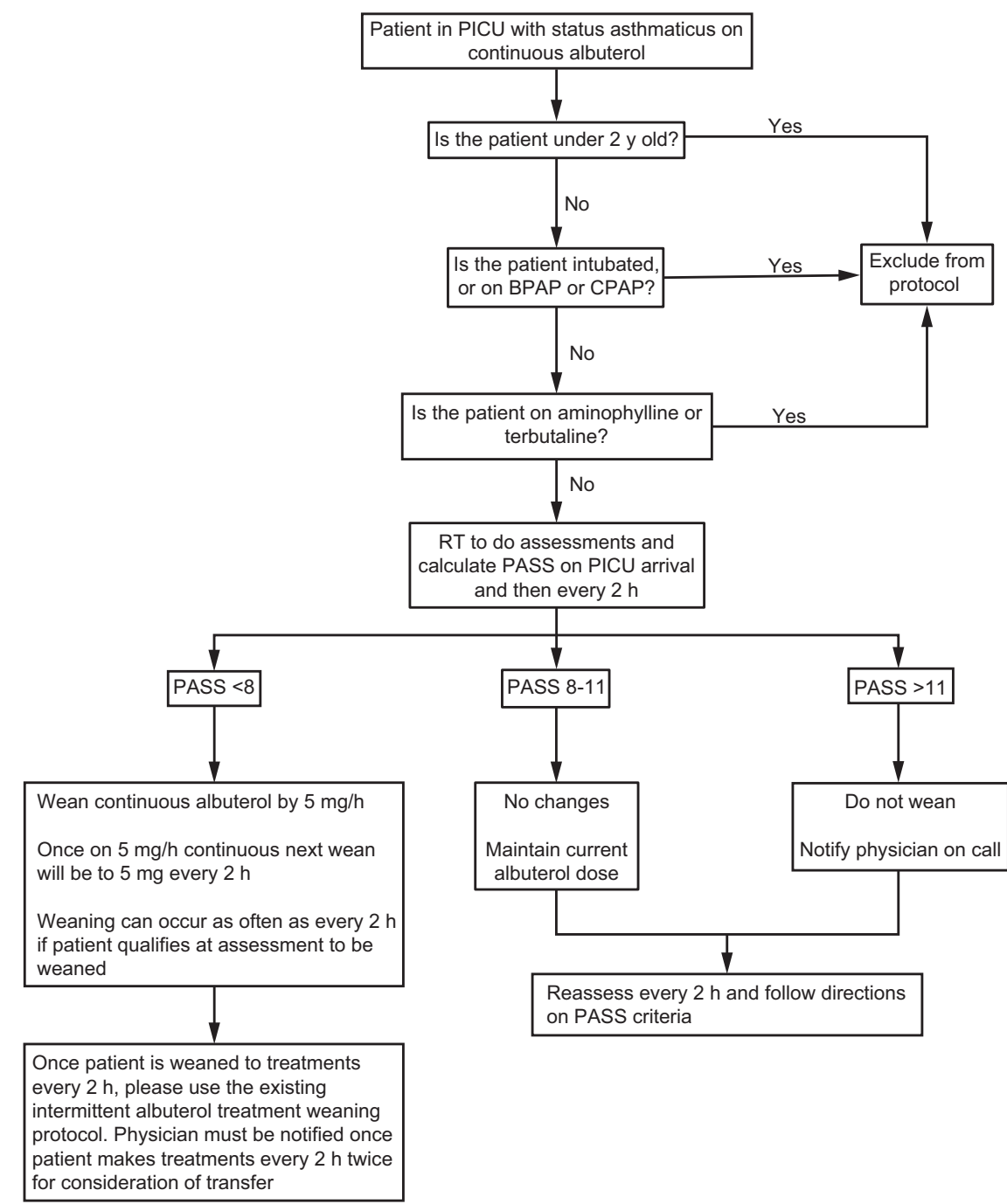

Fig. 1. Continuous albuterol weaning protocol and treatment pathway. BPAP = bi-level positive airway pressure; RT = respiratory therapist; PASS = pediatric asthma severity score; PICU = pediatric ICU.

in the appropriate patients, and to facilitate RT-physician collaboration. The duration of continuous albuterol in the PICU was our primary outcome measure. We also looked at length of PICU stay, defined as starting at the time of admission and ending at the time that transfer orders were written to eliminate confounding by bed availability on the wards. In addition, to ensure the protocol was not overly aggressive, we monitored the rate of adverse events as a balancing measure. Adverse events were defined as the need to restart continuous albuterol, to increase a dose after weaning, or to increase respiratory support after weaning, or readmission to PICU after transfer to the floor. We also monitored significant delays in weaning, which we defined as not being weaned when their PASS score indicated that they were eligible more than once during their treatment without another explanation.

We also aimed to improve RT perceptions of their role in caring for asthma patients in the PICU. Prior to this protocol being implemented, all PICU RTs were sent a link to an anonymous survey in their emails. This survey inquired about their perception of their level of involvement in management decisions regarding asthmatics in the PICU, as well as other related questions. A follow-up survey was sent to their emails after the protocol had been in place for approximately a year, and their answers were recorded and stored.

\section{Statistical Analysis}

Patient demographics and clinical characteristics were compared between the pre-protocol and protocol periods. Descriptive statistics using medians (interquartile ranges) were calculated for continuous variables. Comparison of continuous variables between the groups was performed with the Mann-Whitney $U$ test. Categorical variables were compared using chi-squared or Fisher exact tests, as appropriate. Sta- 


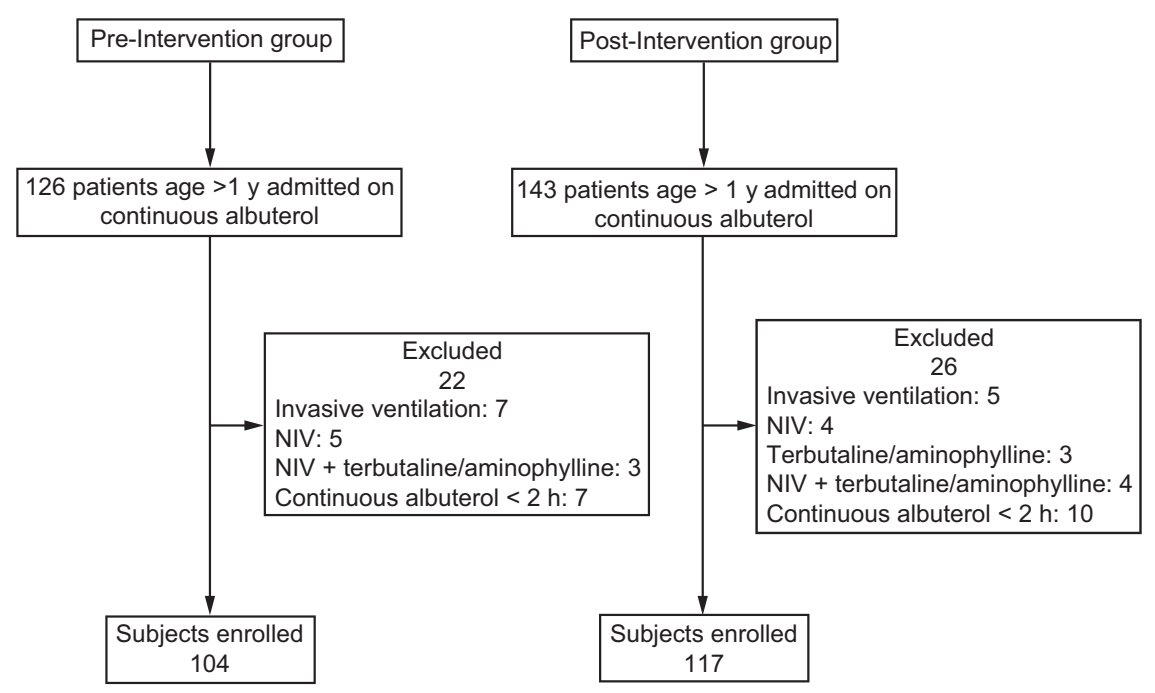

Fig. 2. Flow chart. NIV = noninvasive ventilation.

tistical significance was set at $P<.05$. We used SPSS for Windows, version 20.0 (SPSS, Chicago, Illinois) and Microsoft Office Excel (Redmond, Washington).

SPSS was also used to generate the statistical process control charts of the outcome measures. The upper and lower control limits were calculated as 3 sigma above and below the center line, respectively. We considered 8 consecutive points above or below the control limit to represent a specialcause variation and thus prompt a change in the control limit.

\section{Results}

There were 117 subjects admitted with status asthmaticus who qualified for the protocol in the post-implementation period, compared to 104 subjects in the pre-implementation period. A flow chart illustrating how many patients were excluded from each group is shown in Figure 2. Demographic and baseline clinical characteristics were not significantly different between subjects in each time period (Table 2). Therapies received also did not differ significantly between the groups (Table $3)$. There was no difference in the number of adverse events (Table 4).

The median duration of continuous albuterol in the PICU post-implementation group was $12.1(7.2-21.0) \mathrm{h}$ compared to the pre-implementation group's median duration of $11.1(6.0-19.0) \mathrm{h}$. The median length of PICU stay in the post-implementation group was $19.5(14.3-29.7) \mathrm{h}$ compared to $23.2(15.2-31.3) \mathrm{h}$ in the pre-implementation group. Neither of these were statistically significant, with $P$ values of .22 and .16, respectively. On the X-bar control charts using means, both the duration of albuterol treatment and length of PICU stay were stable, and neither met criteria for special-cause variation (Fig. 3, Fig. 4). The point at which the protocol was initially implemented is shown
Table 2. Subject and Clinical Characteristics

\begin{tabular}{|c|c|c|c|}
\hline Variable & $\begin{array}{l}\text { Pre-Intervention } \\
\text { Group }\end{array}$ & $\begin{array}{l}\text { Post-Intervention } \\
\text { Group }\end{array}$ & $P$ \\
\hline Age, y & $6(4.3-10)$ & $8(4-11)$ & .18 \\
\hline Gender & & & .58 \\
\hline Male & $62(59.6)$ & $75(64.1)$ & \\
\hline Female & $42(40.4)$ & $42(35)$. & \\
\hline Race & & & .28 \\
\hline White/Caucasian & $32(30.8)$ & $42(35.8)$ & \\
\hline African-American & $67(64.4)$ & $74(63.2)$ & \\
\hline Asian & $2(1.9)$ & 0 & \\
\hline Other/Not specified & $3(2.9)$ & $1(0.9)$ & \\
\hline Ethnicity & & & .041 \\
\hline Hispanic/Latinx & $5(4.8)$ & $16(13.7)$ & \\
\hline Non-Hispanic/Latinx & $99(95.2)$ & $101(86.3)$ & \\
\hline Documented history of asthma & $93(89.4)$ & $112(95.7)$ & .12 \\
\hline Controller use & $66(63.5)$ & $83(70.9)$ & .25 \\
\hline Bacterial infection & $11(10.6)$ & $9(7.8)$ & .49 \\
\hline Route of admission & & & .99 \\
\hline Emergency room & $81(77.9)$ & $91(77.8)$ & \\
\hline Direct & $11(10.6)$ & $12(10.3)$ & \\
\hline Floor transfer & $12(11.5)$ & $14(12.0)$ & \\
\hline Admission PASS score & $9(8-10)$ & $9(8-10)$ & .26 \\
\hline \multicolumn{4}{|c|}{$\begin{array}{l}\text { For the pre-intervention group, } n=104 \text { subjects; for the post-intervention group, } \\
n=117 \text { subjects. Data are presented as } n(\%) \text { except for age and PASS score, which are } \\
\text { shown as mean (interquartile range). } \\
\text { PASS = Pediatric Asthma Severity Score }\end{array}$} \\
\hline
\end{tabular}

on both figures. When interim data were reviewed at the 6-month mark with our group of physicians, the decision was made to change the protocol to allow the RTs to wean patients from $10 \mathrm{mg} / \mathrm{h}$ to intermittent treatments instead of weaning from $10 \mathrm{mg} / \mathrm{h}$ to $5 \mathrm{mg} / \mathrm{h}$ prior to intermittent treatments. This change was implemented in April 2017 and is designated on both figures. Although criteria for special-cause vari- 


\section{RT-Driven Albuterol Weaning Protocol}

Table 3. Adjunctive Therapies Used in the Post-Intervention Group Compared to the Pre-Intervention Group.

\begin{tabular}{|c|c|c|c|}
\hline Variable & $\begin{array}{l}\text { Pre-Intervention } \\
\text { Group }\end{array}$ & $\begin{array}{c}\text { Post-Intervention } \\
\text { Group }\end{array}$ & $P$ \\
\hline Steroids & $104(100)$ & 117 (100) & N/A \\
\hline Magnesium sulfate & $93(89.4)$ & $112(95.7)$ & .12 \\
\hline Ipratropium bromide & $86(82.7)$ & $98(83.8)$ & .86 \\
\hline Starting $\mathrm{F}_{\mathrm{IO}_{2}}$ & $0.4(0.3-0.5)$ & $0.4(0.3-0.5)$ & .33 \\
\hline Peak $\mathrm{F}_{\mathrm{IO}_{2}}$ & $0.48(0.35-0.6)$ & $0.4(0.35-0.6)$ & .95 \\
\hline $\begin{array}{l}\text { Heated high-flow } \\
\text { nasal cannula }\end{array}$ & $29(27.9)$ & $29(24.8)$ & .65 \\
\hline \multicolumn{4}{|c|}{$\begin{array}{l}\text { For the pre-intervention group, } n=104 \text { subjects; for the post-intervention group, } \\
n=117 \text { subjects. Categorical values displayed as } n(\%) \text { and were compared with the Fisher } \\
\text { exact test. Continuous variables displayed as median (interquartile range) and were compared } \\
\text { with the Mann-Whitney } U \text { test. }\end{array}$} \\
\hline
\end{tabular}

Table 4. Adverse Outcomes Compared Between the Pre-Intervention and Post-Intervention Groups

\begin{tabular}{cccc}
\hline \hline Outcome & $\begin{array}{c}\text { Pre-Intervention } \\
\text { Group }\end{array}$ & $\begin{array}{c}\text { Post-Intervention } \\
\text { Group }\end{array}$ & $P$ \\
\hline $\begin{array}{c}\text { Increase respiratory } \\
\text { support after wean }\end{array}$ & $1(1.0)$ & $1(0.9)$ & $>.99$ \\
$\begin{array}{c}\text { Pediatric ICU } \\
\text { readmission }\end{array}$ & $1(1.0)$ & $1(0.9)$ & $>.99$ \\
$\begin{array}{l}\text { Increase albuterol } \\
\text { dose after wean }\end{array}$ & $3(2.9)$ & $4(3.4)$ & $>.99$ \\
$\begin{array}{c}\text { Need to restart } \\
\text { continuous albuterol }\end{array}$ & $2(1.9)$ & $2(1.7)$ & $>.99$ \\
\end{tabular}

For the pre-intervention group, $n=104$ subjects; for the post-intervention group,

$n=117$ subjects. Data are presented as $n(\%)$.

ation was still not met after this change, there was a trend toward a shorter duration of continuous albuterol as well as shorter length of PICU stay.

Table 5 shows RT opinions with regard to their role in the treatment of patients with asthma on continuous albuterol before and after implementation of the protocol according to the survey that was sent out. Overall, their outlook significantly improved regarding their level of involvement as well as the efficiency in weaning.

\section{Discussion}

In this quality-improvement project, we developed and implemented a safe, RT-driven, continuous albuterol weaning protocol in the PICU that resulted in stable duration of treatment and length of PICU stay. Protocols and standardization of practice can make processes more efficient, improve outcomes, and maintain or improve safety. ${ }^{8,9}$ In busy, high-acuity PICUs, collaboration between various members of the medical team is essential for effective and efficient care to be delivered to all patients. Protocols developed by interdisciplinary teams may allow for improved RT autonomy to assess these patients and make independent decisions regarding the care of these patients.

The patient population in both study periods were similar in terms of demographics and clinical therapies received. There is a significantly higher Hispanic/Latinx population in the post-intervention group, but it is unclear whether this has any clinical importance. There was also a trend toward more magnesium sulfate use in the postintervention group. Otherwise, there were no clear differences between the groups.

During the implementation period, there was no significant change in the duration of continuous albuterol treatment or length of PICU stay. When interim data were reviewed in March 2017, it was noted that there was no significant change. Because we were aiming for a decrease in duration of continuous albuterol, we proposed a modification to the protocol. After discussing with our group of intensivists and RTs, we decided to modify the protocol so that the 5-mg/h step was removed, which would in theory shorten treatment duration. This change went into effect in early April 2017. Since that time, it appears that the duration of continuous albuterol treatment and length of PICU stay have started to decrease, but these changes were not significant at the time that the study concluded. It is possible that a significant change may have been observed if data had been collected for a longer period.

A recent study performed at another institution using a protocol with similar asthma severity scores showed that their protocol reduced the duration of continuous albuterol treatment. ${ }^{14}$ However, there were key differences between their study and ours that make any comparison difficult. For example, in their protocol, the standard therapies that subjects received at the beginning of the protocol included not only continuous albuterol and steroids, but also ipratropium bromide, which most but not all of our subjects received. If a subject was not able to wean within $4 \mathrm{~h}$, a chest radiograph was obtained and the subject was placed on heliox as long as there was no contraindication. ${ }^{14}$ This protocol was more aggressive than ours, and while our institution does use heliox in some cases for severe asthmatics, it is not a standard therapy. Criticisms of heliox include lack of high-quality evidence and high cost. ${ }^{15-18}$ However, there are some studies that show it could be beneficial, ${ }^{19,20}$ so it is possible that this could have contributed to the shorter duration of continuous albuterol treatment in their study. ${ }^{14}$

One strength of our protocol is that the rate of adverse events did not change. Adverse events are relatively rare in this population, and it is reassuring that this did not change with the protocol. Another strength of our protocol is that it is completely RT-driven, with a PASS score threshold established to trigger physician involvement. This allows the RT to have independence to the fullest extent of their 


\section{RT-Driven Albuterol Weaning Protocol}

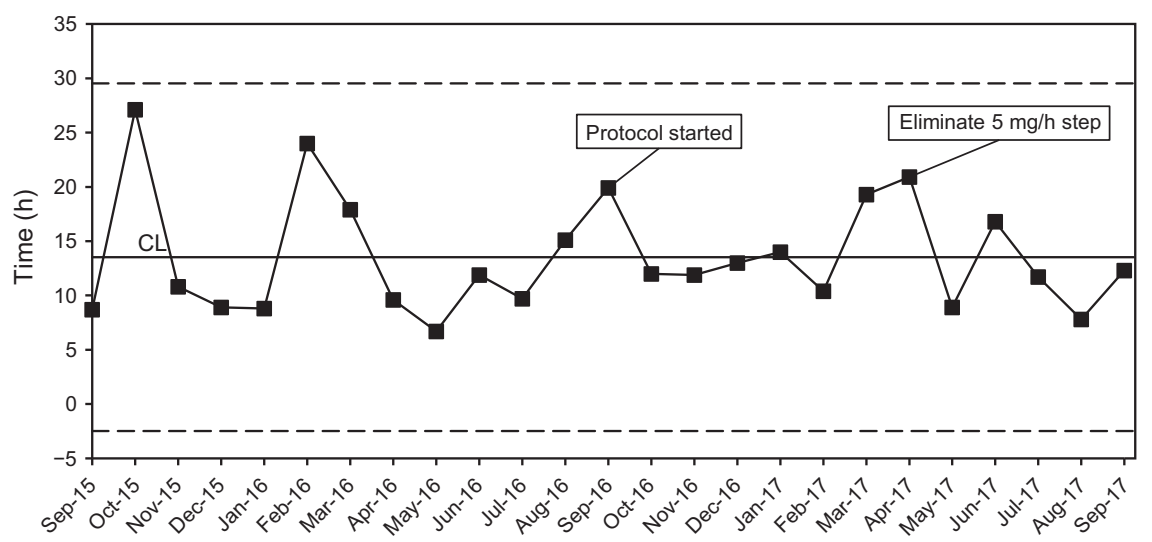

Fig. 3. Control X-bar chart demonstrating the change in median pediatric ICU duration of continuous albuterol over the study period. The $x$ axis shows each month of the study sequentially, and the $y$ axis shows time in hours. Each point is the median duration of continuous albuterol for the indicated month. The solid line is the center line, and dashed lines denote upper and lower control limits. The protocol start point and the point of protocol change are shown. This did not meet criteria for special-cause variation.

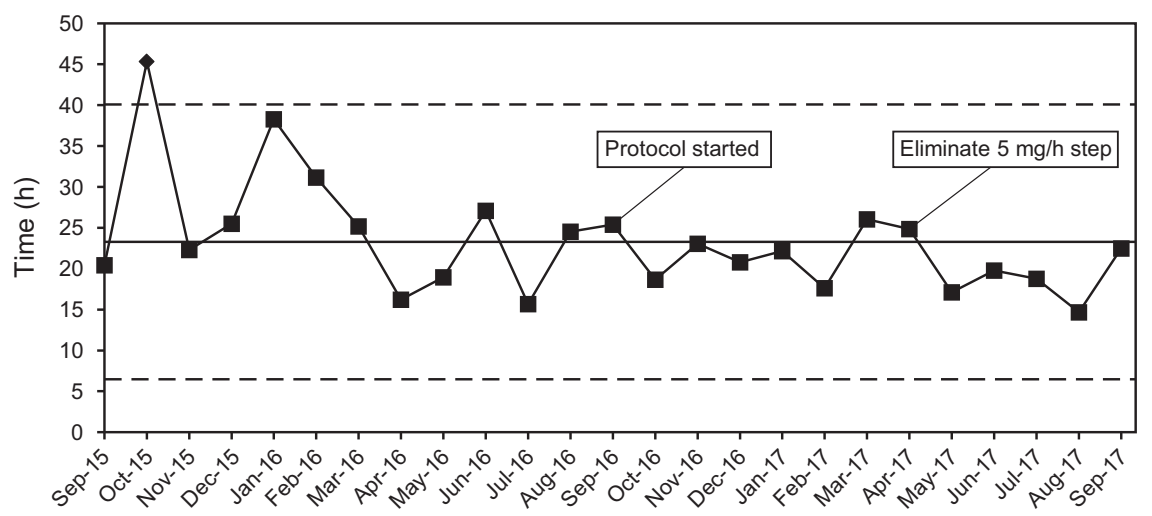

Fig. 4. Control X-bar chart demonstrating the change in median pediatric ICU length of stay over the study period. The $x$ axis shows each month of the study sequentially, and the $y$ axis shows time in hours. Each point is the median length of stay for the indicated month. The solid line is the center line, and dashed lines denote upper and lower control limits. The protocol start point and the point of protocol change are shown. There was a trend toward shorter length of stay, but it did not meet criteria for special-cause variation.

Table 5. Results of the Respiratory Therapist Satisfaction Survey

\begin{tabular}{|c|c|c|c|}
\hline Survey Question & $\begin{array}{l}\text { Pre-Intervention } \\
\text { Group }\end{array}$ & $\begin{array}{l}\text { Post-Intervention } \\
\text { Group }\end{array}$ & $P$ \\
\hline Is your level of involvement in the management decisions of asthmatics in the PICU appropriate? & $17(39.5)$ & $26(86.7)$ & $<.001$ \\
\hline Is the speed at which we wean continuous albuterol in the PICU appropriate? & $14(32.6)$ & $21(70)$ & .002 \\
\hline Is RT input not being incorporated a barrier to weaning continuous albuterol efficiently? & $19(44.1)$ & $5(16.7)$ & .01 \\
\hline Is physician availability a barrier to weaning continuous albuterol efficiently? & $8(18.6)$ & $2(6.7)$ & .13 \\
\hline
\end{tabular}

For the pre-intervention group, $n=43$ subjects; for the post-intervention group, $n=30$ subjects. Data are "Yes" responses and are presented as $n$ (\%). Compared with the Fisher exact test.

PICU $=$ pediatric ICU

$\mathrm{RT}=$ respiratory therapist

scope of practice, and even though this protocol actually added relative value units to the RT work load, it was still looked upon favorably. This is likely because the RTs enjoyed having more input and control over patient care, which could in turn make them feel more valued and po- tentially could help reduce burnout. It has been shown across disciplines that burnout is often associated with decreased job satisfaction and can be linked to worse patient outcomes. ${ }^{21,22}$ This has not been formally studied in RTs, but this would likely apply to them as well. This 


\section{RT-Driven Albuterol Weaning Protocol}

protocol also improves RT-physician collaboration by allowing each team member to apply their unique skill sets where it is best suited. This is particularly helpful in a busy, high-acuity ICU.

\section{Limitations}

This study is a quality-improvement initiative at a single center and thus may not be generalizable to all other centers. It is possible that other factors on the unit may have influenced the results. For example, if the PICU is at capacity, the team will be more likely to transfer a patient out as soon as they meet criteria, even if it is the middle of the night, whereas if the unit has bed availability, there is a greater likelihood of waiting until morning to put in transfer orders. Our use of the electronic medical record to determine length of PICU stay creates inherent limitations. For example, time of PICU admission was determined from the first set of charted vitals after arrival to the unit. While this is generally done quickly, it could be delayed by as much as $20-30 \mathrm{~min}$. There is no way to completely overcome this variability, but we feel that this existed for both the pre-intervention and the post-intervention groups.

\section{Conclusions}

An inter-professionally developed RT-driven continuous albuterol weaning protocol can be successfully implemented in a PICU. In our experience, an RT-driven protocol using PASS scores did not negatively impact the duration of continuous albuterol treatment or the length of PICU stay, and such a protocol can be safely implemented without increasing adverse events. Furthermore, it also improves RT perceptions regarding their role in care of asthmatic patients in the PICU.

\section{REFERENCES}

1. Centers for Disease Control and Prevention. National Surveillance for Asthma-United States, 1980-2004. MMWR Surv Summ 2007; 56(SS08);1-14;18-54.

2. Benneyworth B, Rigby R, Heskett M, Carroll A, Nitu M. Using all patient refined diagnosis related group to identify cost-management targets. Pediat Therapeut 2014;4:217.

3. Children's Health Care of Colorado Asthma Clinical Care Guidelines. Available at:https://www.ihconline.org/media/cms/Childrens_Hospital_ Colorado_asthmac_147F03BB6763A.pdf. Accessed February 15, 2019.

4. Gorelick MH, Scribano PV, Stevens MW, Schultz T, Shults J. Predicting need for hospitalization in acute pediatric asthma. Pediatr Emerg Care 2008;24:735-744.
5. Gorelick MH, Stevens MW, Schultz TR, Scribano PV. Performance of a novel clinical score, the Pediatric Asthma Severity Score (PASS), in the evaluation of acute asthma. Acad Emerg Med 2004;11:10-18.

6. Maue DK, Krupp N, Rowan CR. Pediatric asthma severity score is associated with critical care interventions. World J Clin Pediatr 2017; 6(1):34-39.

7. Mitra A. The current role of intravenous aminophylline in acute paediatric asthma. Minerva Pediatr 2003;55(4):369-375.

8. Rotter T, Kinsman L, James E, Machotta A, Willis J, Snow P, Kugler J. Clinical pathways: effects on professional practice, patient outcomes, length of stay and hospital costs. Cochrane Database Syst Rev 2010;17(3):CD006632.

9. Rice S. Consistent high performers. Truven 100 Top Hospitals focus on standardization to improve outcomes and reduce costs. Mod Healthcare 2015;45(9):14-19.

10. Ely EW, Bennett PA, Bowton DL, Murphy SM, Florance AM, Haponik EF. Large scale implementation of a respiratory therapistdriven protocol for ventilator weaning. Am J Respir Crit Care Med 1999;159:439-446.

11. Robertson TE, Mann HJ, Hyzy R, Rogers A, Douglas I, Weinert C, et al. Multicenter implementation of a consensus-developed, evidence-based spontaneous breathing trial protocol. Crit Care Med 2008;36(10):2753-2762.

12. Schultz TR, Lin RJ, Watzman HM, Durning SM, Hales R, Woodson A, et al. Weaning children from mechanical ventilation: a prospective randomized trial of protocol-directed versus physician-directed weaning. Respir Care 2001;46(8):772-782.

13. Harris PA, Taylor R, Thielke R, Payne J, Gonzalez N, Conde JG. Research electronic data capture (REDCap): a metadata-driven methodology and workflow process for providing translational research informatics support. J Biomed Inform 2009;42(2):377-381.

14. Wong J, Agus MS, Graham DA, Melendez E. A critical asthma standardized clinical and management plan reduces duration of critical asthma therapy. Hosp Pediatr 2017;7(2):79-87.

15. Rivera ML, Kim TY, Stewart GM, Minasyan L, Brown L. Albuterol nebulized in heliox in the initial ED treatment of pediatric asthma: a blinded, randomized controlled trial. Am J Emerg Med 2006;24(1):3842.

16. Hashemian SM, Fallahian F. The use of heliox in critical care. Int J Crit Illn Inj Sci 2014;4(2):138-142.

17. Chevrolet JC. Helium oxygen mixtures in the intensive care unit. Crit Care 2001;5(4):179-181.

18. Leatherman JW, Romero RS, Shapiro RS. Lack of benefit of heliox during mechanical ventilation of subjects with severe air flow obstruction. Respir Care 2018;63(4):375-379

19. Rodrigo GJ, Castro-Rodriguez JA. Heliox-driven $\beta 2$-agonists nebulization for children and adults with acute asthma: a systematic review with meta-analysis. Ann Allergy Asthma Imunol 2014;112(1):29-34.

20. Rehder KJ. Adjunct therapies for refractory status asthmaticus in children. Respir Care 2017;62(6):849-865.

21. Aiken LH, Clarke SP, Sloane DM, Sochalski J, Silber JH. Hospital nurse staffing and patient mortality, nurse burnout and job satisfaction. JAMA 2002;288(16):1987-1993.

22. Panagioti M, Geraghty K, Johnson J, Azou A, Panagopoulou E, ChewGraham C, et al. Association between physician burnout and patient safety, professionalism, and patient satisfaction: a systematic review and meta-analysis. JAMA Intern Med 2018;178(10):1317-1330.

This article is approved for Continuing Respiratory Care Education credit. For information and to obtain your CRCE

(free to AARC members) visit www.rcjournal.com

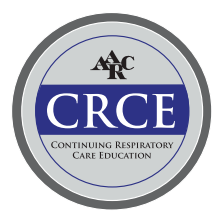

